\section{俩 Heighten Science P U B L I C I T I O N S Corporation ISSN 2576-9537}

\title{
Intra-abdominal testicular tumour--A case report
}

\author{
Sardar Rezaul Islam¹, Shafiqur Rahman², Shahalam Sarkar ${ }^{3}$ \\ and Debabrata Paul ${ }^{3}$ \\ 'Professor \& Head, Department of Surgery, JIMCH, Bangladesh \\ ${ }^{2}$ Professor, Department of Radiology and imaging, $\mathrm{JIMCH}$, Bangladesh \\ ${ }^{3}$ Registrar, Department of Surgery, Bangladesh
}

\footnotetext{
*Address for Correspondence: Sardar Rezaul Islam, MBBS, FRCSEd, Professor \& Head, Department of Surgery, Jahurul Islam Medical College, Bajitpur, Kishoreganj, Bangladesh, Tel: 01746603305; E-mail:islamreza@hotmail.com

Submitted: 21 September 2018

Approved: 16 October 2018

Published: 17 October 2018
}

Copyright: ๑ 2018 Islam SR, et al. This is an open access article distributed under the Creative Commons Attribution License, which permits unrestricted use, distribution, and reproduction in any medium, provided the original work is properly cited

Keywords: Undescended testis; Testicular cancer; Seminoma

Check for updates

\section{Abstract}

A 35-year-old man presented with swelling in the lower abdomen for 2 months. He was found to have left undescended testis. An ultrasound scan showed a solid floating pelvic mass. His chest $x$-ray and tumour markers for testicular cancer were normal. Exploratory laparotomy revealed the left intra-abdominal testicular tumour. Intra-abdominal left orchiectomy was performed. The patient made an uneventful recovery. Histology showed immature seminoma. A mass in the lower abdomen with a cryptorchidic testis strongly points towards the diagnosis of malignancy in abdominal testis. To prevent this complication all undescended testis gets orchiopexy before 2nd year or orchiectomy in post-adolescent life. But some cases remain unnoticed, which leads to this kind of presentation. So, we decided to present this rare and interesting case of intra-abdominal testicular tumour.

\section{Introduction}

During fetal development, the testes develop in the abdomen and later descend into the scrotal sac in the third trimester, usually between weeks 28 to 32 . During the descent, it may be arrested anywhere along its tract (cryptorchidism) or may migrate into an abnormal position (ectopic testis). The most common sites of undescended testis are high scrotal, canaliculi, abdominal, and bilateral [1]. Cryptorchidism, the most common congenital anomaly of the genitourinary tract in males, is encountered in $1 \%$ of boys [2]. In cryptorchid testicles, the incidence of testicular cancer is considered to be 3 to 48 times greater than in the general population. Testicular cancer is developed in $10 \%$ of the cases with descendent testicles [3], various tumour markers are available in the form of alpha fetoprotein ( $\alpha$-FP), beta human chorionic gonadotrophin ( $\beta$-HCG), lactate dehydrogenase (LDH), and placenta-like alkaline phosphatase. They are helpful not only in making the diagnosis but also in formulating a management plan. Their sensitivity and specificity vary according to the type of testicular tumour [4].

\section{Case Report}

A 35-year-old man presented with central abdominal pain for a period of 8 months. Then he noticed swelling in lower abdomen for previous 2 months. There was a palpable floating mass in the left lower abdomen. There was underdeveloped hemiscrotum and absent left testis. He had a small penis and a small right testis. He also gave history of sexual dysfunction, loss of libido and infertility. He had no gynaecomastia. An ultrasound scan of the abdomen showed a solid pelvic mass $65 \mathrm{~mm} \times 50 \mathrm{~mm}$. There were no enlargement of intra abdominal lymph nodes. A-fetoprotein and HCG were within normal limit. X-ray chest was also found to be normal. Exploratory laparotomy was performed. A pedunculated mass was found arising from left side of the pelvis. It was 
thought to be left intra-abdominal testicular tumour. Left orchiectomy was performed. No abdominal lymphanopathy detected on laparotomy. The patient made an uneventful recovery. He was kept on surveillance. Histology showed immature seminoma. This patient was of average built and stature. He did not have gynaecomastia. He had axillary hair and male distribution of pubic hair. We could not perform chromosomal analysis. Considering his severe hypogonadism a possibility of mosaic variety Klinefelter's syndrome could not be ruled out. His testicular cancer was staged as stage-I seminoma. So put the patient for active surveillance.

\section{Discussion}

In humans, testes develop in the abdomen and normally descend into the lower portion of the scrotum during the third trimester. During the descent, it may be arrested anywhere along its tract (cryptorchidism) or may migrate into an abnormal position (ectopic testis). The most common sites of undescended testis are high scrotal (50\%), canaliculi (20\%), and abdominal (10\%), bilateral (10\%) [1], the cancer risk of an ectopic testis is 50 times higher than normal testis. Inguinal testis has 11 time more chance of malignant transformation than normal one [2]. The cancer of undescended testes usually peaks in the third or fourth decade of life [2].

Tumour in an abdominal testis is more likely to be seminoma, but tumours in testes previously corrected by orchipexy are more likely to be non-seminomas [5].

Malignancy in undescended intra-abdominal testes are more likely to be seminomas. Seminoma is a germ cell neoplasm of the testis. Non seminomatous germ cell tumour is also reported in intra-abdominal testis. A case was reported where a 35 years old man presented with abdominal mass and left undescended testis. It was operated and found to be stage IIB non-seminomatous germ cell tumour. Patient received post-operative chemotherapy [6]. In this respect our case was diagnosed at a very early stage. No post-operative adjuvant treatment was needed. A case of testicular seminoma was reported in a female with testicular feminization syndrome and crytorchid testis [7]. There are reported cases where orchidopexy was done for inguinal testis in one side but contralateral testis remained intra-abdominal. Testicular cancer developed from that intra-abdominal testis. Often it is difficult to locate rudimentary intra-abdominal testis by CT scan or even MRI. As a result nothing could be done at that situation and future intra-abdominal testicular malignancy becomes inevitable (Figures 1,2).

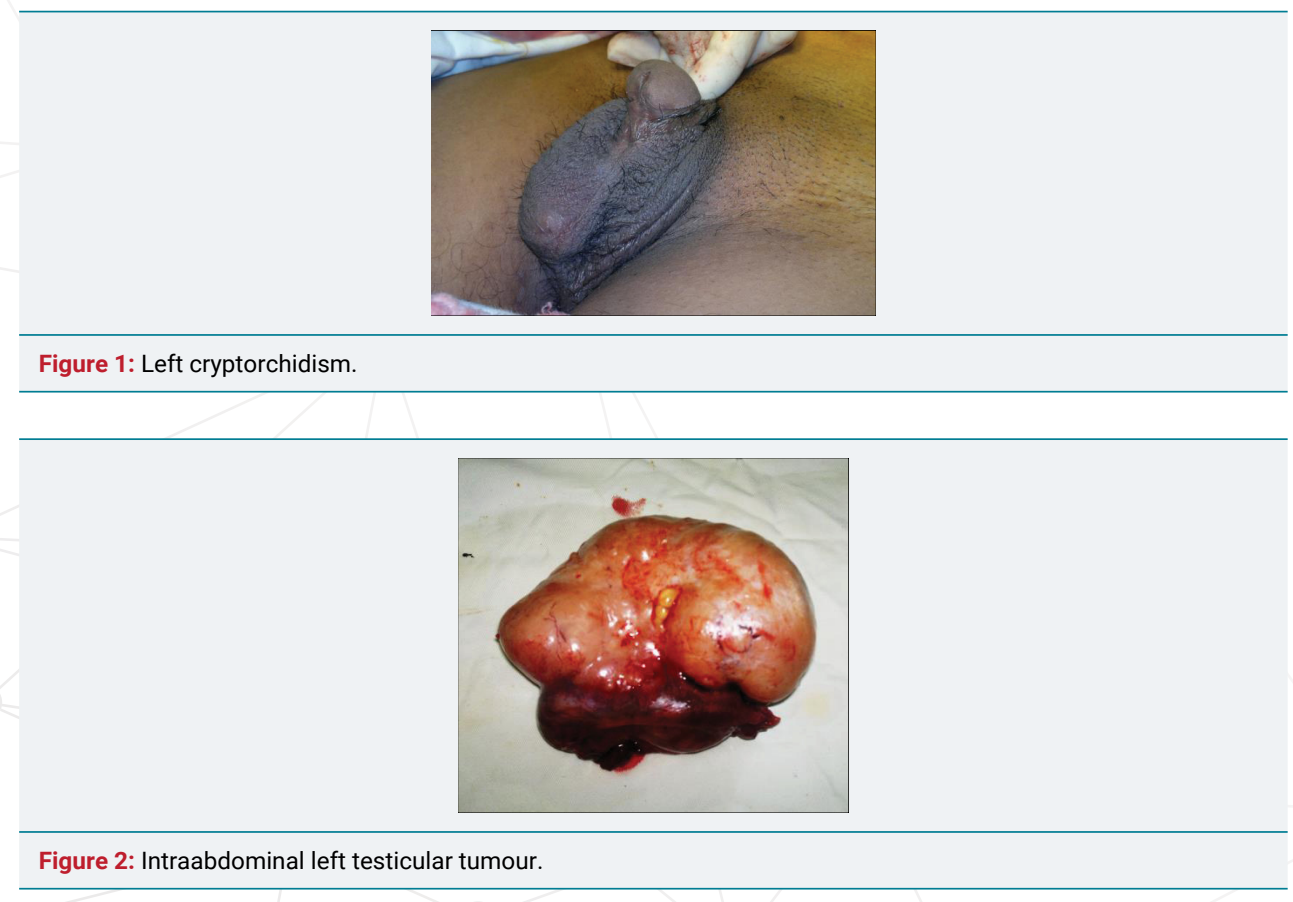


Reason of malignant transformation of undescendent testis remains unclear. Two hypotheses have been proposed to explain this association. The first one says that local temperature elevation of an ectopic testis is, somehow, procarcinogenic. If this hypothesis is true, then orchidopexy (testis descend and fixation in the scrotum) could protect against cancer if the procedure is performed before precancerous cells differentiate to a critical point such as that of puberty. The second hypothesis says that an underlying hormonal condition predisposes to both cryptorchidism and testicular cancer. If so, orchidopexy would not prevent the testicular cancer and orchidectomy would be required [2].

A high intra-abdominal temperature has been incriminated as the cause of carcinogenesis in the testis. There may be a decrease in the spermatogenesis, Leidig cell abnormality, and delay in the development of the Sertoli cells in the testis, leading to infertility [6]. In our case, there was infertility and sexual dysfunction. Painless enlargement of the testis, or abdominal mass, is the common mode of manifestation in a cryptorchid testis. Rarely, an abdominal testicular tumour can present with torsion, massive abdominal mass and pain. Sometimes haematuria can be presentation due to infiltration to the urinary bladder [8].

Various imaging modalities are available to diagnose and stage of this condition. Classically, scrotal ultrasonography shows hypoechoic intratesticular mass in seminoma and some calcification and cystic changes in nonseminomas. CT scanning of the abdomen and the pelvis is a very sensitive tool for the metastatic evaluation, which definitely helps plan the management [9]. Chest $\mathrm{x}$-ray is needed for evaluation of blood born metastasis.

In developed countries, the existence of undescended testicles in the adult population is rare, which is due to systematic practice of elective orchidopexy before the second year of life to prevent cancer and infertility. Still many cases of intra-abdominal testicular tumours are reported from western world also. Orchidopexy does not eliminate cancer risk but allows an early diagnosis by making testicles accessible to exploration [3]. About $5 \%-20 \%$ of patients with a cryptorchid testis develop a testicular tumor on the opposite, normally descended, testis. Some authors suggest that prophylactic orchiectomy of the uninvolved testis as the preferred option. With all available information and considering his hypogonadism state we declined to manipulate the opposite testis.

Testicular cancers are highly curable, even in patients with metastatic disease at diagnosis. The prognosis depends upon the histologic type of cancer (seminoma versus non-seminoma), staging, and other features such as tumor markers and type of metastatic disease.

Dramatic improvements in survival have resulted from the combination of effective diagnostic techniques, improvement in serum tumor markers, effective multi-drug chemotherapeutic regimens and modifications of surgical techniques during last twenty years. According to American Joint Cancer Commission (AJCC) risk classification our patient falls under good risk, stage I seminoma which has $85 \%$ chance of 5 year survival. Post-operative chemo-radiotherapy was not needed only he was put on active suveilance.He was seen after 6 months with no sign of recurrence [11].

\section{Conclusion}

An undescended testis, whenever possible, must be brought down into its normal scrotal position within school going age. Our patient presented in adult life with a floating abdominal swelling with absent testis in the same side of hemi-scrotum. Laparotomy and excision of the mass was appropriate treatment for this patient. Patients with crytorchid testis, if presented in childhood, should be investigated with CT or MRI to locate the testis and orchiectomy performed. That only can avoid such cases of intraabdominal testicular malignancy. 


\section{Reference}

1. Dahnert W. Radiology review manual. 5th ed. Williams and Wilkins; 2003. Testicular tumour. 925.

2. Alshyarba MH. A giant intra-abdominal testicular seminoma. Biomed Res. 2010; 21: 227-229. Ref.: https://goo.gl/TXUha4

3. Cristian PC, Cristobel B, Macaroni R. New case of an intra-abdominal testicular seminoma in an adult. Actus Uro Esp. 2007; 31: 160-163. Ref.: https://goo.gl/qc8dXN

4. Shrestha B, Vaidya JL. Unresolved abdominal mass. Kathmandu Univar Med J. 2009; 7: 82-85. Ref.: https://goo.gl/NVFA1m

5. Chandrasekhar LV, Abdul Gaffer T, Venkatramana M, Ratho S. A Case Of Teratocarcinoma In Abdominal Testis: A Case Report. Internet J Radiol. 2005; 4. Ref.: https://goo.gl/y83obb

6. Iwamura H, Hatakeyama S, Fukushi K, Sato T, Kojima Y. Testicular tumor arising in intra-abdominal testis which was not detected at prior orchidopexy: a case report. Hiniyokika Kiyo. 2013; 59: 189-193. Ref.: https://goo.gl/QF6Wbz

7. Rasalkar DD, Paunipagar BK, Ng A, Lai FM, Bagaria SJ. Intra-Abdominal Testicular Seminoma in a Woman with Testicular Feminization Syndrome. Case Report in Radiology. 2011; 5. Ref.: https://goo.gl/xykxUH

8. Haque $M M$, Siddique $A B$, Rabbani $A B M G$, Quasem MA, Rahman AKMG, et al. Seminoma in undescended intra abdominal testis: a case report. TAJ: J Teachers Association. 2005; 18: 131-133. Ref.: https://goo.gl/Sr2kvo

9. Joseph C, Presti JR. Genital tumours. In: Tanagho EA, McAninch JW, editors. Smith's general urology. 17th edition. New York, NY: Lange Medical Books/McGraw-Hill, Medical Publishing Division; 2008; 375-382.

10. Batata MA, Chu FC, Hilaris BS, Whitmore WF, Golbey RB, et al. Testicular cancer in cryptorchids. Cancer. 1982; 49: 1023-1030. Ref.: https://goo.gl/GBMcBH

11. Kush Sachdeva, Mansoor Javeed, Brendan Curti. Testicular cancer. e-medicine. 2009. 